\title{
Experimental Investigation and Statistical Analysis of Low Frequency RFID System
}

DOI : 10.36909/jer.ICCEMME.15555

\author{
Shilpa Choudhary ${ }^{1 *}$, Abhishek Sharma ${ }^{2}$, Arpana Mishra $^{3}$
}

${ }^{1}$ Department of Electronics and Communication Engineering, G L Bajaj Institute of Technology and Management, Greater Noida, UP, India.

${ }^{2}$ Department of Mechanical Engineering, G L Bajaj Institute of Technology and Management, Greater Noida, UP, India.

${ }^{3}$ Department of Electronics and Communication Engineering, IIMT, Greater Noida, India.

*Email id: shilpadchoudhary@ gmail.com; Corresponding author

\begin{abstract}
In today's era RFID system plays a key role in the field of asset tracking but its maximum read range or detectability may get degraded due to the challenges which are being provided by varying atmospheric conditions. So, to study the effect of these challenging atmospheric conditions, experimental investigation and statistical analysis of RFID system detectability has been carried out. Varying surrounding temperature, humidity and the presence of soil layer thickness in between RFID reader and tag and its five different grain sizes were considered as input parameters. All these observations were carried out for three different soils i.e. sandy soil, Silt and clay. Execution of test was carried out according to the MINITAB 17 tool. According to ANOVA analysis as well as from interaction plot it was found that soil layer thickness have more impact on RFID system read range and $\mathrm{R}^{2}$ value was found to be $96.91 \%, 99.64 \%$ and $99.78 \%$ for RRSS, RRS and RRC respectively. Composite desirability of optimization was found to be 0.8425 . Optimum values of process parameters
\end{abstract}


Temperature, Soil Layer Thickness, Relative Humidity and Soil Grain Size were found to be $303.3^{\circ} \mathrm{K}, 2.5 \mathrm{~cm}, 40.1 \%, 1.92 \mathrm{~mm}$ respectively. Best values of responses were found to be $10.94 \mathrm{~cm}$ for (Read Range in presence of Clay); $11.02 \mathrm{~cm}$ (Read Range in presence of Silt) and $10.97 \mathrm{~cm}$ (Read Range in presence of Sandy Soil).

Keywords: read range; ANOVA; detectability; optimization.

\begin{tabular}{|l|l|l|l|}
\hline \multicolumn{4}{|c|}{ Nomenclature } \\
\hline Temperature & Temp & $\begin{array}{l}\text { Read Range in presence of sandy } \\
\text { soil }\end{array}$ & RRSS \\
\hline Relative Humidity & RH & Read Range in presence of silt & RRS \\
\hline Soil Layer Thickness & ST & Read Range in presence of clay & RRC \\
\hline Design of Experiments & DOE & Analysis of variance & ANOVA \\
\hline Soil Grain Size & SGS & Radio Frequency Identification & RFID \\
\hline
\end{tabular}

\section{INTRODUCTION}

Supply chain management is a field where RFID has been used commonly. It helps in enhancing the efficiency in the manufacturing and improvement of logistics. In recent years health monitoring, asset tracking, environment monitoring are the criteria's where these technologies are emerging at a rapid pace. Although these technologies would be more apt for the fields like defense or military since these areas are more sensitive and it can be dangerous if the go to irresponsible hands so handling of the information in the defense and military field should be done wisely. On contrary to this the benefits of asset tracking technology in defense can result into more optimized and usage of asset and can make increment in the safety and security of the country. Use of RFID system makes this tracking system more reliable and advancing as the tracking timing is decreased and also cost is reduced as there is reduction in the manual efforts with even more accuracy rate. Though it has so many advantages but still it faces to many challenges due to the environment in which we use it. Detectability of RFID tag antenna gets directly affected by the general environment condition like variation in temperature, humidity, dust storm etc. At one point these condition are so worst that the tags 
becomes unreadable even if it is in the readable range as a result of which the asset gets untraceable and the advantages of RFID remains uncertain.

Looking at these scenarios where environment affects the system, this work was preceded in the presences of various environmental conditions in which RFID system would be installed such as arid or semi-arid regions.

\section{RELATED WORK}

In data capturing technology, the RFID and barcoding are two important key factors. Danial Abdorahimi et al. reviewed the working principle of modified-Friis and Complex Refractive Index Model-Fresnel (CRIM-Fresnel) and concluded the greater attenuation in dense participating contents of soil and water (Abdorahimi et al., 2019). Barcoding is very traditional method required some printing area on goods. In contrast of barcoding RFID is more preferable. Human power is not required to read data in RFID capturing. By Yung -Chang Hsieh et al. used different experimental materials fabricating antennas of frequency $13.56 \mathrm{MHz}$ in their frame work .Squeegee angle, squeegee speed and blade hardness etc. have been considered as key factors in their experiment (Hsieh et al., 2011). Tae-Hoon Kim et al. discussed many results affected from thermal variation on self-generating and non-self-generating RFID tags. Passive RFID tag has no requirement of extra energy source. Noise attenuation can affect the reading of RFID (Kim et al., 2017).Fangming Deng et al. compared the communication success rate in presence of errors ranging from $1.5 \%$ to $1.0 \%$ with car speed of $33 \mathrm{~km} / \mathrm{hrs}$. They included errors in respect of temperature and moisture. In present scenario most of the landfarming monitoring technology is based on RFID. By using monopole antenna RFID in communication, size of antenna can be reduced (Deng et al., 2020).SannaLahoKallio et al. reported the various thermal cycling effects on conductive RFID systems. Anisotopic conductive adhesive (ACA) system in RFID can provide better reading in variable atmospheric condition (Saarinen et al., 2014). According to Sabina Manzari et al. conclusion a curved and 
folded shaped RFID tags made-up of PEDOT: PSS are best suitable for food conservation and medical field (Manzariet al., 2012). According to Choudhary et al. consideration of EM4100 family transponders provide better results within $10-15 \mathrm{~km}$ far range and $125 \mathrm{KHz}$ frequency. Provided data from RFID is strongly dependent on environmental conditions (Choudhary et al., 2019).The evaluation of water levels in soil have been done using two existing methods by Sergio Francisco Pichorim et al. They evaluated double tags and SL900A PCB process (Pichorim et al., 2018). Choudhary et al. plotted the main effect of received signal strength for LTE (RSSSLTE) technology by using MIMITAB17 software including relative humidity and air quality as main accounting parameters in variable temperature of atmosphere (Choudhary et al., 2020).Sharma et al. optimized engine input parameters by using dual optimization technique Taguchi and RSM (Sharma et al., 2020).

Main objective of this work is to use the RSM technique to utilize the best combination of input variable to get highest output that too with minimum number of tests. So in this research work, the atmosphere temperature (TEMP), relative humidity (RH), soil layer thickness (SLT) and soil grain size (SGS) were considered as input parameters and Read Range for Sandy Soil (RRSS), Read Range for silt (RRS) and Read Range for Clay (RRC) were considered as system responses.

\section{MATERIALS AND METHODS}

The experiment setup used for simulating the varying atmospheric condition was within a glass chamber as shown in Figure 1 and components used are as shown in Table 1 with their technical specifications. 


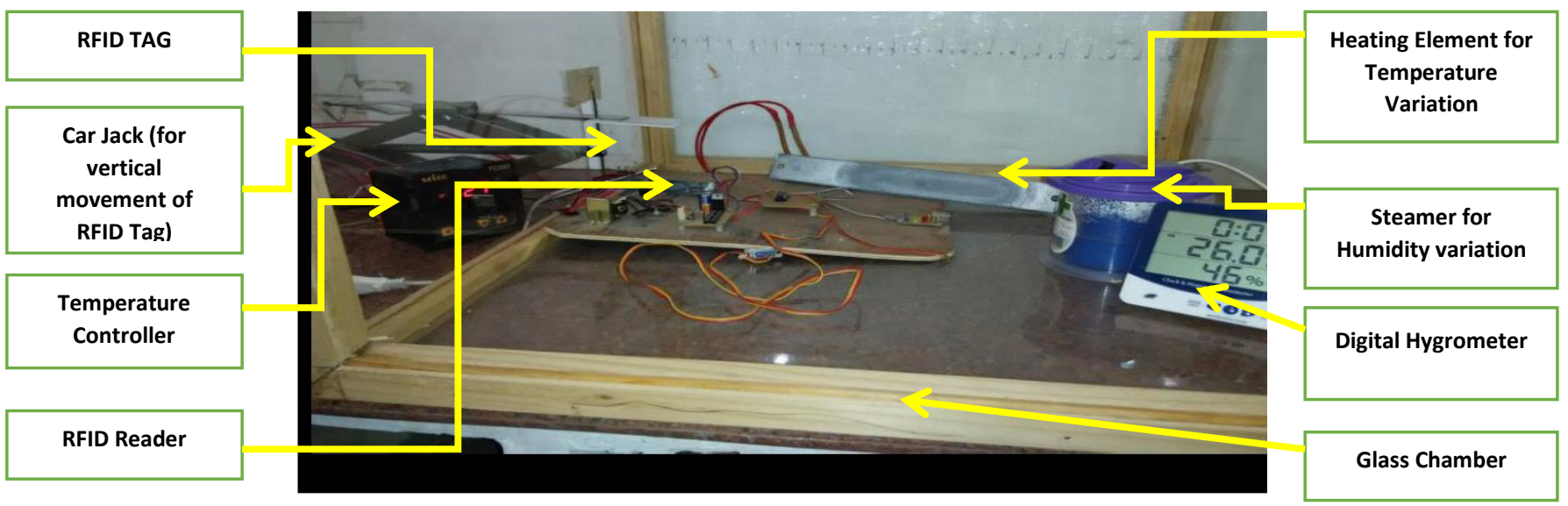

Figure 1 Experiment setup with varying temperature, humidity and soil layer thickness between RFID tag and Reader.

The outcome of this experiment was the variation in RFID system read range when three different types of soils ( sand, silt and clay) are present in between the RFID tag and the reader with five different soil grain sizes i.e. $0.45 \mathrm{~mm}, .78 \mathrm{~mm}, 1.18 \mathrm{~mm}, 1.6 \mathrm{~mm}$ and $2 \mathrm{~mm}$, varying humidity and temperature around the system. Input parameter ranges considered for experiment is as shown in Table 2.

Table1 Components Used

\begin{tabular}{|c|c|}
\hline Components Used & Technical Specifications \\
\hline RFID Tag and Reader form EM4100 family & $\begin{array}{l}\text { 1. Reading Distance } 10-15 \mathrm{CM} \text { of the reader } \\
\text { 2. } 125 \mathrm{KHz} \text { read frequency } \\
\text { 3. } 9600 \mathrm{Baud} \mathrm{RS}-232 \text { Serial interface } \\
\text { 4. Standard } 2.54 \mathrm{~mm} \text { Pitch Bergstrip connector } \\
\text { 5. Low power Requirement } 7-9 \mathrm{~V} @ 100 \mathrm{~mA} \\
\text { 6. Dimensions : } 63 \mathrm{~mm} \times 98 \mathrm{~mm} \times 5 \mathrm{~mm} \\
\text { 7. Operating temperature range : }-40 \text { to }+85^{\circ} \mathrm{C} \text {. }\end{array}$ \\
\hline $\begin{array}{l}\text { Digital Vernier Caliper ( for measurement } \\
\text { of thickness of soil layer and RFID system } \\
\text { readability range) }\end{array}$ & $\begin{array}{l}\text { 1. Measuring Range: } 0-150 \mathrm{~mm} / 0-6 \mathrm{in} . \\
\text { 2. Resolution: } 0.01 \mathrm{~mm} / 0.0005 \mathrm{in} . \\
\text { 3. Accuracy: } \pm 0.02 \mathrm{~mm} / 0.001 \mathrm{in} .(<100 \mathrm{~mm}) ; \pm 0.03 \mathrm{~mm} \\
\text { / 0.001in. }(>100 \mathrm{~mm}) \text {. } \\
\text { 4. Repeatability: } 0.01 \mathrm{~mm} / 0.0005 \mathrm{in} . \\
\text { 5. Measuring Speed ( Maximum): } 1.5 \mathrm{~m} / \mathrm{second} \\
\text { 6. Measuring System: Linear Capacitive Measuring } \\
\text { System. } \\
\text { 7. Display: LCD } \\
\text { 8. Power: LR44 }(1.5 \mathrm{~V} / 180 \mathrm{mAh}) \\
\text { 9. Working Temperature: } 5^{\circ} \mathrm{C}-40^{\circ} \mathrm{C}\end{array}$ \\
\hline
\end{tabular}




\begin{tabular}{|c|c|}
\hline Temperature Controller & $\begin{array}{l}\text { 1. } 7 \text { Segment LED Single Display } \\
\text { 2. Thermocouple (J,K,T,R,S) / RTD (PT100) type input } \\
\text { 3. Control Output: RELAY or SSR } \\
\text { 4. Accuracy: For TC (J, K, T) inputs: } 0.25 \% \text { of F.S. } \pm 1 \text { : } \\
\text { For R \& S inputs: } 0.5 \% \text { of F.S. } \pm 2(20 \mathrm{~min} \text { of warm up } \\
\text { time) For RTD inputs: } 0.1 \% \text { of F.S } \pm 1 \\
\text { 5. Supply Voltage: } 85 \text { to } 270 \text { V AC / DC } \\
\text { 6. Size: } 96 \text { x } 96 \mathrm{~mm} \\
\text { 7. Mounting Type: Panel Mount } \\
\text { 8. Certification: CE }\end{array}$ \\
\hline Heating element & $\begin{array}{l}\text { 1. Power Consumption } 60 \mathrm{~W} \\
\text { 2. Supply Voltage: } 12 \mathrm{~V} \\
\text { 3. Material: Aluminum } \\
\text { 4. Input current : } 0.5-1 \mathrm{~A}\end{array}$ \\
\hline Digital Hygrometer & $\begin{array}{l}\text { 1. Temperature Measuring range: } \\
\text { Indoor: } 10 \sim+50^{\circ} \mathrm{C}\left(+14 \sim+122^{\circ} \mathrm{F}\right) \\
\text { Outdoor:50 +70 } \mathrm{C}\left(-58 \sim+158^{\circ} \mathrm{F}\right) \\
\text { 2. Humidity measure range: } 20 \sim 99 \% \mathrm{RH} \\
\text { 3. Accuracy: }+/-1^{\circ} \mathrm{C},+/-5 \% \mathrm{RH}\end{array}$ \\
\hline $\begin{array}{l}\text { Steamer ( (To vary chamber humidity } \\
\text { ranging from } 35 \% \mathrm{RH} \text { to } 75 \% \mathrm{RH} \text { ) }\end{array}$ & $\begin{array}{l}\text { 1. Power Consumption } 20 \mathrm{~W} \\
\text { 2. Tank Size : } 500 \mathrm{ml}\end{array}$ \\
\hline
\end{tabular}

\section{RESULTS AND DISCUSSION}

RSM mathematical modeling used to find optimum solution. Main purpose to use the RSM technique to utilize the best combination of input variable to get highest output that too with minimum number of tests. In certain fields it can be used and have no application based constraint. The most fruitful and best among architecture available is the middle composite rotating architecture which is adept by adding two lab experiment level along each coordinate axis at opposite direction of the origin and at a distance same to the semi-diagonal of the hypercube of the factorial architecture and new extreme values (low and high) for each factor added in this architecture. In the previous study the similar statement has been accounted. Different coded level for complete range of input parameters is as shown in Table 2. Table 3 shown experimental outcomes which were found after executing the experiments as per CCRD. 
Table 2 Coded range for experiments

\begin{tabular}{|c|c|c|c|c|c|c|}
\hline Factors or input & \multirow{2}{*}{$\begin{array}{c}\text { Unit } \\
\text { parameters }\end{array}$} & & \multicolumn{5}{|c|}{ Coded Levels } \\
\cline { 3 - 7 } & & $\mathbf{- 2}$ & $\mathbf{- 1}$ & $\mathbf{0}$ & $\mathbf{1}$ & $\mathbf{2}$ \\
\hline Temperature & ${ }^{\circ} \mathrm{C}$ & 288 & 293 & 298 & 313 & 323 \\
\hline Soil Layer Thickness & $\mathrm{cm}$ & 0 & 2.5 & 4.5 & 6.5 & 9 \\
\hline Relative humidity & $\% \mathrm{RH}$ & 35 & 44 & 52 & 61 & 70 \\
\hline Soil Grain Size & $\mathrm{mm}$ & 0.45 & 0.78 & 1.18 & 1.6 & 2 \\
\hline
\end{tabular}

MINITAB 17 generates experimental design with four input parameters at five levels as shown by Table 2 .

Table 3: L31 Experiment array

\begin{tabular}{|c|l|l|l|l|c|c|c|}
\hline $\begin{array}{l}\text { Exp. } \\
\text { Run }\end{array}$ & $\begin{array}{l}\text { Temp. } \\
\left({ }^{\mathbf{} K}\right)\end{array}$ & $\begin{array}{l}\text { ST } \\
(\mathbf{C m})\end{array}$ & $\mathbf{R H}$ & $\mathbf{T})$ & $\begin{array}{c}\text { Read } \\
\text { Range } \\
\text { for } \\
\text { Sandy } \\
\text { Soil } \\
(\mathbf{c m})\end{array}$ & $\begin{array}{c}\text { Read } \\
\text { Range } \\
\text { for silt } \\
(\mathbf{c m})\end{array}$ & $\begin{array}{c}\text { Read } \\
\text { Range } \\
\text { for Clay } \\
(\mathbf{c m})\end{array}$ \\
\hline 1 & 313 & 6.5 & 61 & 1.60 & 10.71 & 10.61 & 10.41 \\
\hline 2 & 298 & 4.5 & 52 & 1.18 & 10.86 & 10.81 & 10.65 \\
\hline 3 & 298 & 4.5 & 52 & 1.18 & 10.84 & 10.80 & 10.65 \\
\hline 4 & 298 & 4.5 & 70 & 1.18 & 10.83 & 10.74 & 10.50 \\
\hline 5 & 313 & 2.5 & 61 & 0.78 & 10.86 & 10.86 & 10.67 \\
\hline 6 & 293 & 2.5 & 61 & 0.78 & 10.89 & 10.90 & 10.70 \\
\hline 7 & 313 & 6.5 & 61 & 0.78 & 10.69 & 10.57 & 10.36 \\
\hline 8 & 293 & 2.5 & 44 & 1.60 & 10.95 & 10.99 & 10.90 \\
\hline 9 & 293 & 2.5 & 61 & 0.78 & 10.89 & 10.90 & 10.70 \\
\hline 10 & 298 & 4.5 & 52 & 0.45 & 10.83 & 10.78 & 10.60 \\
\hline 11 & 298 & 4.5 & 52 & 1.18 & 10.84 & 10.80 & 10.65 \\
\hline
\end{tabular}




\begin{tabular}{|c|c|c|c|c|c|c|c|}
\hline 12 & 298 & 4.5 & 35 & 1.18 & 10.88 & 10.87 & 10.79 \\
\hline 13 & 293 & 6.5 & 44 & 1.60 & 10.77 & 10.70 & 10.58 \\
\hline 14 & 298 & 4.5 & 52 & 1.18 & 10.85 & 10.80 & 10.65 \\
\hline 15 & 298 & 4.5 & 52 & 2.00 & 10.89 & 10.84 & 10.71 \\
\hline 16 & 313 & 6.5 & 44 & 0.78 & 10.71 & 10.63 & 10.50 \\
\hline 17 & 293 & 6.5 & 61 & 1.60 & 10.75 & 10.63 & 10.44 \\
\hline 18 & 288 & 4.5 & 52 & 1.18 & 10.81 & 10.79 & 10.63 \\
\hline 19 & 293 & 6.5 & 61 & 0.78 & 10.72 & 10.60 & 10.38 \\
\hline 20 & 298 & 0.0 & 52 & 1.18 & 11.06 & 11.14 & 11.01 \\
\hline 21 & 298 & 9.0 & 52 & 1.18 & 10.66 & 10.47 & 10.29 \\
\hline 22 & 293 & 2.5 & 61 & 1.60 & 10.92 & 10.93 & 10.76 \\
\hline 23 & 298 & 4.5 & 52 & 1.18 & 10.85 & 10.80 & 10.65 \\
\hline 24 & 298 & 4.5 & 52 & 1.18 & 10.84 & 10.80 & 10.65 \\
\hline 25 & 313 & 2.5 & 44 & 1.60 & 10.92 & 10.97 & 10.87 \\
\hline 26 & 313 & 6.5 & 44 & 1.60 & 10.74 & 10.67 & 10.55 \\
\hline 27 & 313 & 2.5 & 61 & 1.60 & 10.89 & 10.91 & 10.73 \\
\hline 28 & 293 & 6.5 & 44 & 0.78 & 10.74 & 10.66 & 10.52 \\
\hline 29 & 298 & 4.5 & 52 & 1.18 & 10.84 & 10.80 & 10.65 \\
\hline 30 & 313 & 2.5 & 44 & 0.78 & 10.89 & 10.93 & 10.81 \\
\hline 31 & 323 & 4.5 & 52 & 1.18 & 10.76 & 10.75 & 10.60 \\
\hline
\end{tabular}

\section{ANOVA ANALYSIS}

The numerical evidence on the value of possibility is provided through a variance analysis (ANOVA). The ANOVA results of RRS, RRC and RRSS are shown in Table 4. The variance analysis technique was used on the various input parameters to determine the significance of each parameter within the specified range. According to the program, these findings were obtained using the linear regression model. The p-value is the most crucial parameter in ANOVA findings. From the ANOVA results, the p-value is considered the most important factor. Awad et al. stated that the p-value of various parameters must be not more than 0.05 
and the parameters having a p-value greater than 0.05 are considered as not important (Awad et al., 2017). The variables having p-values less than 0.05 indicates that the variable has a great impact on the developed model. From Table 2, it clears that for RSS, RRC and RRSS p-value is less than 0.05 .

Table 4 ANOVA results for RRSS, RRS and RRC

\begin{tabular}{cccccccc}
\hline & \multicolumn{4}{c}{ RRSS } & \multicolumn{2}{c}{ RRS } & \multicolumn{2}{c}{ RRC } \\
\hline Sources & DF & $\begin{array}{c}\text { F- } \\
\text { value }\end{array}$ & $\begin{array}{c}\text { P- } \\
\text { value }\end{array}$ & $\begin{array}{c}\text { F- } \\
\text { value }\end{array}$ & $\begin{array}{c}\text { P- } \\
\text { value }\end{array}$ & $\begin{array}{c}\text { F- } \\
\text { value }\end{array}$ & $\begin{array}{c}\text { P- } \\
\text { value }\end{array}$ \\
Regression & 4 & 203.57 & 0 & 1790.4 & 0 & 2973.4 & 0 \\
Temp (K) & 1 & 37.34 & 0 & 76.48 & 0 & 71.49 & 0 \\
ST (cm) & 1 & 755.27 & 0 & 6869.2 & 0 & 10152 & 0 \\
RH (\%) & 1 & 18.42 & 0 & 281.9 & 0 & 1864.5 & 0 \\
SGS (mm) & 1 & 16.95 & 0 & 97.37 & 0 & 316.56 & 0 \\
Lack-of-fit & 19 & 9.35 & 0.003 & 43 & 0 & 154.38 & 0 \\
\hline
\end{tabular}

The mathematical models have also been tested using a computational approach using the decision coefficient $R^{2}$. Sarıkayaand Güllü(Sarıkaya and Güllü, 2014) believed that that $R^{2}$ values below 1 suggest that the experimental effects are consistent with the findings of the model indicates that the reliability is very strong from Table 5, it is showing that the finding of $\mathrm{R}^{2}$ is $96.91 \%, 99.64 \%$ and $99.78 \%$ for RRSS, RRS and RRC respectively. These values of $\mathrm{R}^{2}$ are nearly close to 1 which indicates that this mode gives reliable results.

Table 5 Model summary

\begin{tabular}{ccccc}
\hline Model & S & $\mathbf{R}^{\mathbf{2}(\%)}$ & Reg. $\mathbf{R}^{\mathbf{2}}(\boldsymbol{\%})$ & Pred. $\mathbf{R}^{\mathbf{2}}(\boldsymbol{\%})$ \\
\hline RRSS & 0.016459 & 96.91 & 96.43 & 95.57 \\
RRS & 0.0091776 & 99.64 & 99.58 & 99.49 \\
RRC & 0.0080274 & 99.78 & 99.75 & 99.7 \\
\hline
\end{tabular}

$\mathrm{R}^{2}$ : Correlation coefficient 


\section{MAIN EFFECTS PLOT}

The main effects plot also gives a rough idea about the relative significance of the parameters on the system response. In the main effect's plots, if the line for a particular parameter is near horizontal, then the parameter has no significant effect. On the other hand, a parameter for which the line has the highest inclination will have the most significant effect. The main effects plots for each are given in Figure 2. Figure 2(a) shows the variation in RFID system read range when the sandy soil (RRSS) is present between the RFID tag and reader. From this figure it can be observed that majorly the soil layer thickness affects the RRSS and it keeps on reducing with increasing soil layer thickness. Whereas, the RRSS is maximum at room temperature and reduces linearly on either sides of room temperature. With increasing RH, RRSS keeps on reducing whereas it shows completely opposite behavior with respect to varying soil grain size. Figure 2(b) and 2(c) shows the main effect plot for RRS and RRC respectively. From these figures same conclusion can be drawn as it was observed for the RRSS.

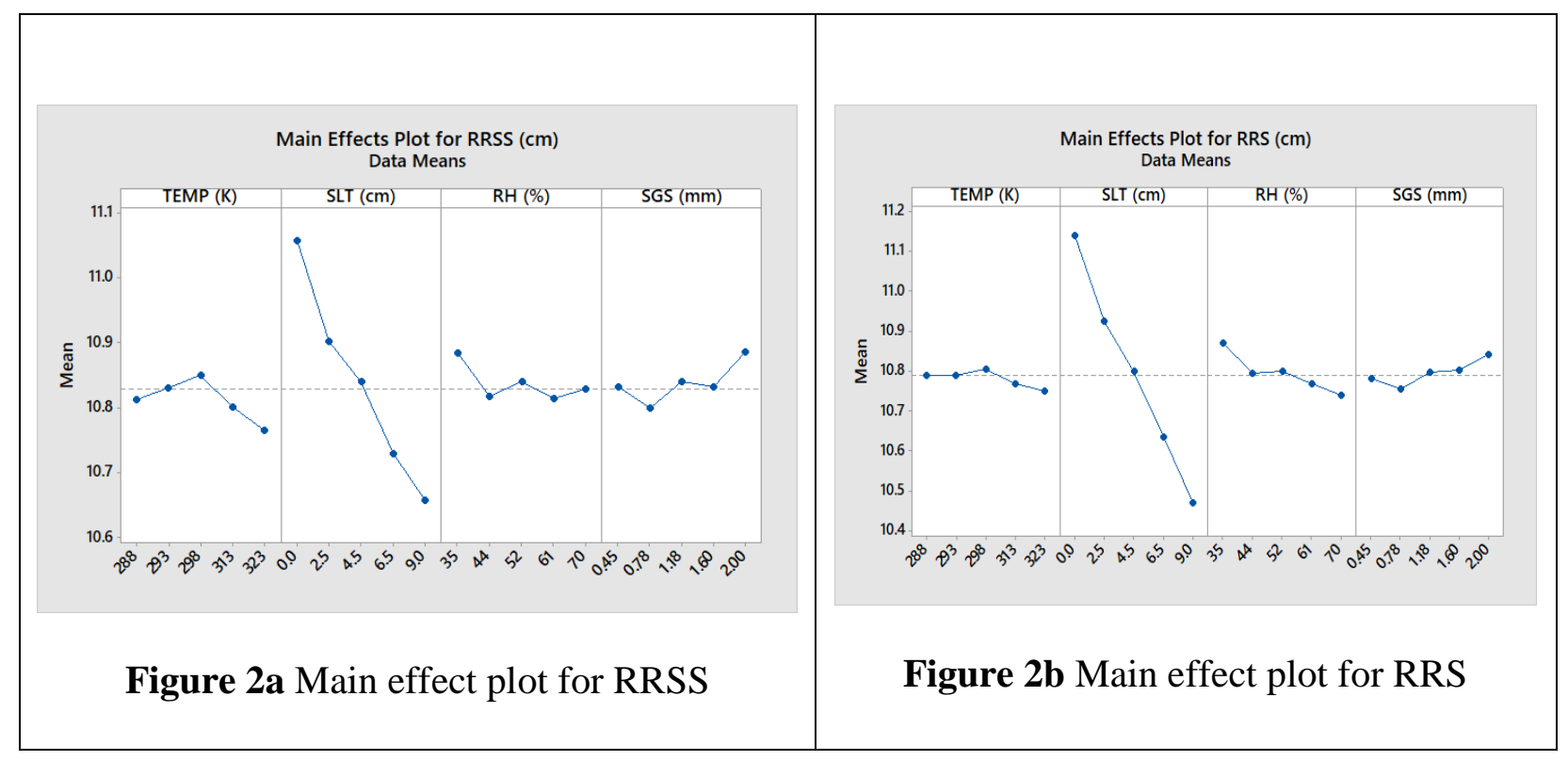




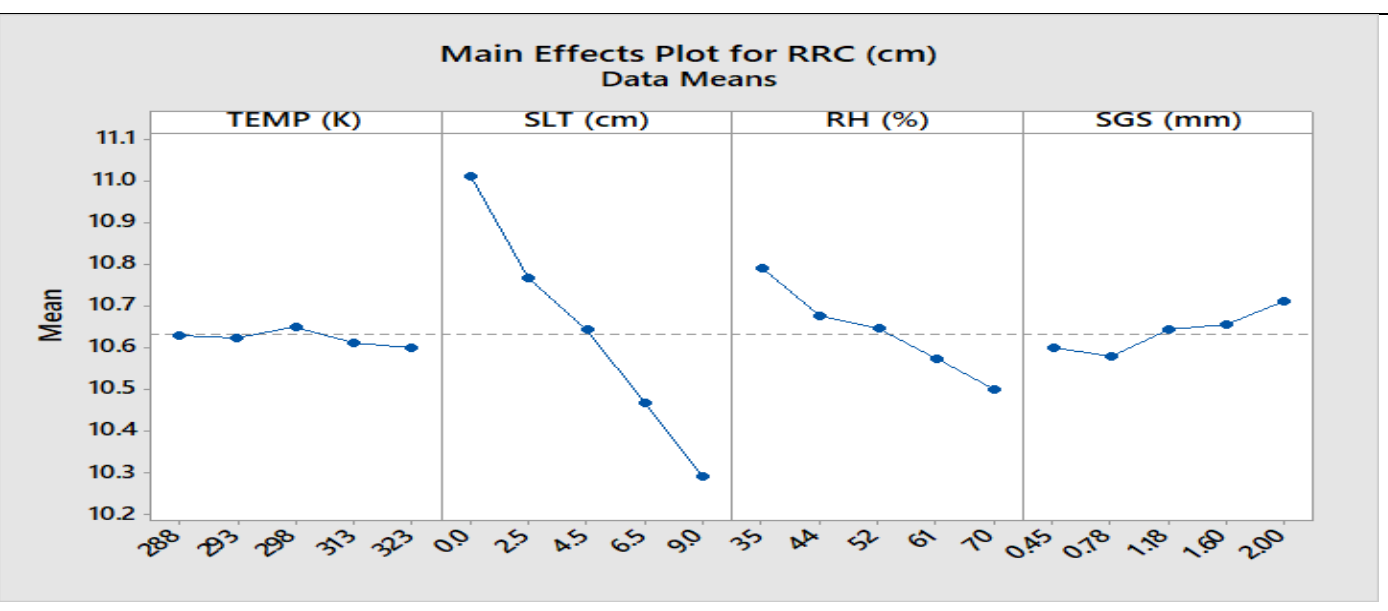

Figure 2c Main effect plot for RRC

From Figure 2(a) to 2(c) it was observed that in presence of clay RFID system read range gets effected drastically whereas presence of sandy soil have very moderate effect on it.

\section{INTERACTION PLOT}

Interaction plot shows how the relationship between one categorical factor and a continuous response depends on the value of the second categorical factor. This plot displays means for the levels of one factor on the $\mathrm{x}$-axis and a separate line for each level of another factor.

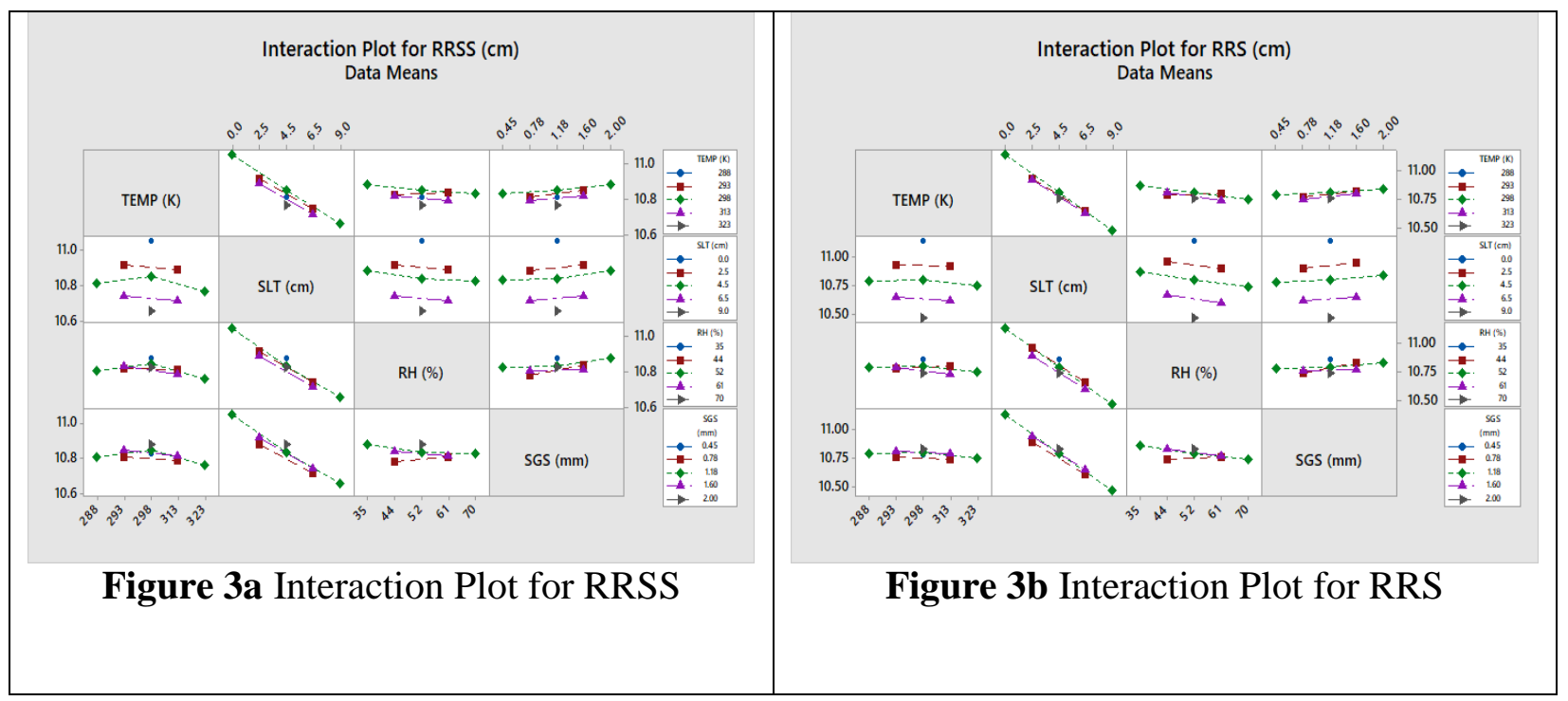




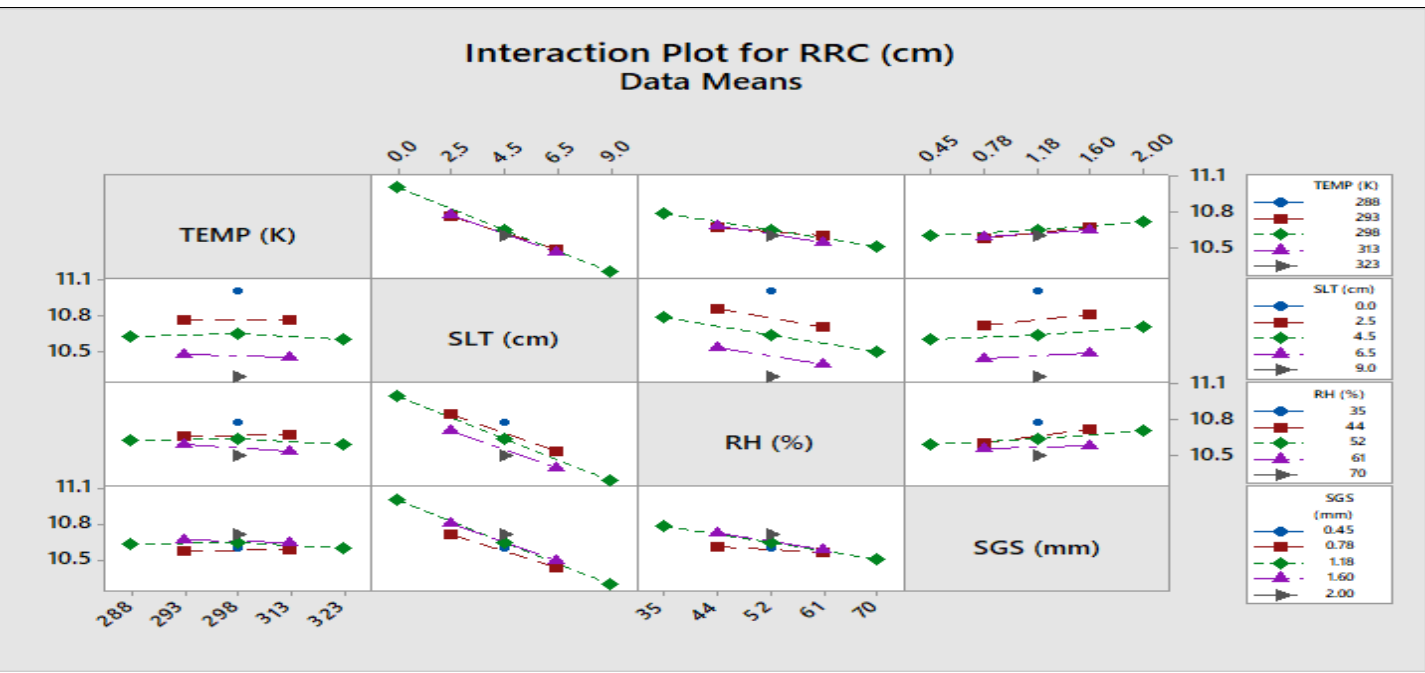

Figure 3c Interaction Plot for RRC

To evaluate the lines to understand how the interactions affect the relationship between the factors and the response. Parallel lines show no interaction whereas nonparallel lines show the occurrence of interaction. More the nonparallel lines, greater is the strength of the interaction. Although we can use this plot to display the effects, be sure to perform the appropriate ANOVA test and evaluate the statistical significance of the effects. If the interaction effects are significant, we cannot interpret the main effects without considering the interaction effects. Figure 3(a) to (c) shows Interaction for RRSS, RRS and RRC respectively with input factors used to understand the behaviour of one variable depends on the value of another variable. Interaction effects are analyzed in regression analysis, DOE (Design of Experiments) and ANOVA (Analysis of variance). From all these figures same conclusion has been drawn as it was concluded from main effect plots (Figure 2) i.e. soil layer thickness have drastic effects on RFID system read range as compare to other input parameters (Relative humidity, soil grain size and temperature) and presence of clay in between the RFID tag and reader may severely affect the system read range whereas the presence of soli have minimum effect on it. 


\section{RSM OPTIMIZER PLOT}

RSM optimizer is shown in by Figure 4, it gives the optimized values of input variables with which best possible value of RFID system read range can be achieved. With same weightage on output responses the multi objective optimization was carried out. The main objective of this research work was to enhance the Output response i.e. RFID system read range in presence of Sandy Soil, Silt and Clay.

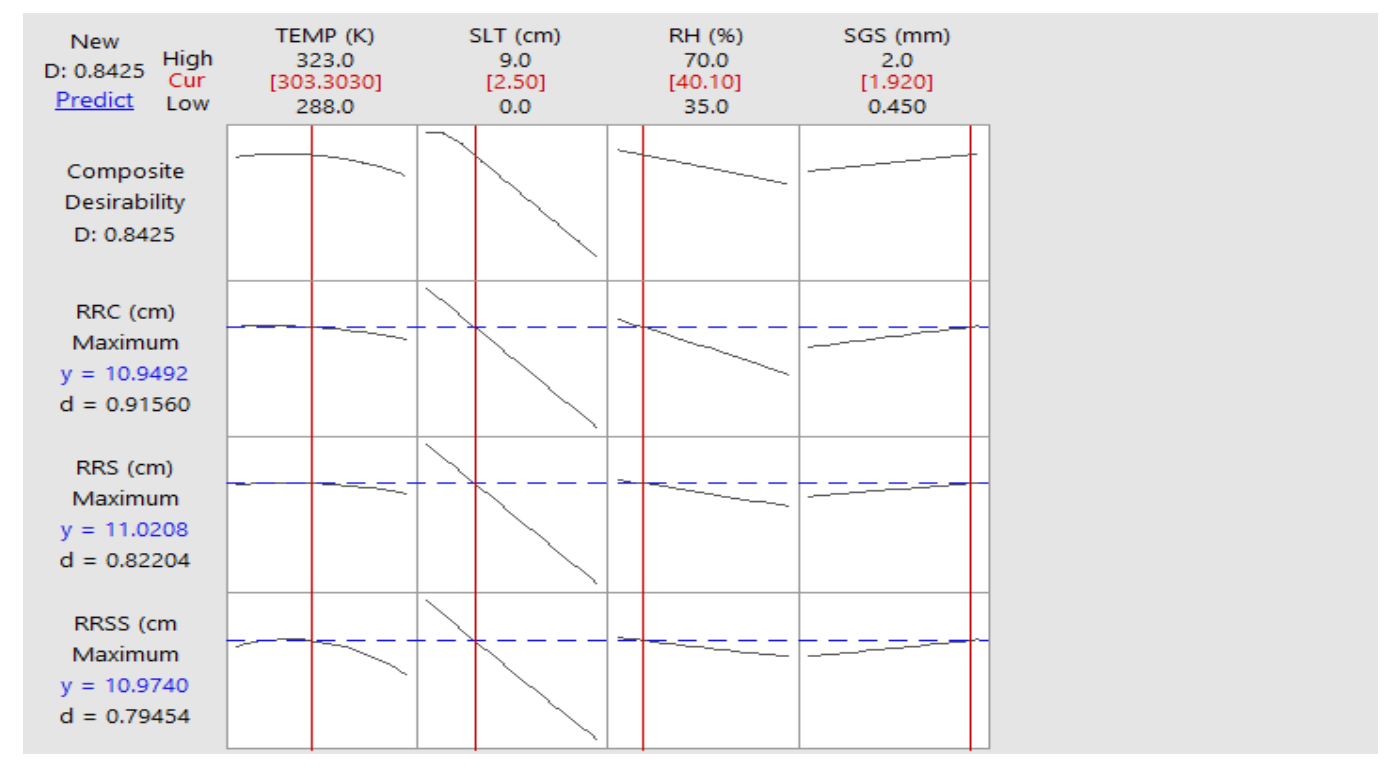

Figure 4 Optimization plot: Impact of input parameters on responses.

Optimum values of inputs Temperature, Soil Layer Thickness, Relative Humidity and Soil Grain Size were found $303.3^{\circ} \mathrm{K}, 2.5 \mathrm{~cm}, 40.1 \%, 1.92 \mathrm{~mm}$ respectively. For the mentioned input setting, optimum responses were found $10.94 \mathrm{~cm}$ for (Read Range in presence of Clay RRC); $11.02 \mathrm{~cm}$ (Read Range in presence of Silt - RRS) and $10.97 \mathrm{~cm}$ (Read Range in presence of Sandy Soil - RRSS). Composite desirability of optimization was 0.8425 that shows favorable indication of optimization process for Read Range of RFID System. 


\section{CONCLUSIONS}

This research work was carried out for the statistical analysis of read range or the detectability of low frequency RFID system. All the experiments were performed according to MINITAB 17 software. Details of system parameters and conclusions drawn from the work is as mentioned below-

- Interaction plot as well as ANOVA analysis shows that soil layer thickness has more impact on RFID system read range as compared to other input parameters.

- Input parameters which were considered for the analysis were Temperature (288 $\mathrm{K}$ to $323 \mathrm{~K}$ ), Relative Humidity (35\%RH to $70 \% \mathrm{RH})$, Soil Layer Thickness (0 $\mathrm{cm}$ to $9 \mathrm{~cm})$ and Soil Grain Size $(0.45 \mathrm{~mm}$ to $2.0 \mathrm{~mm})$.

- $\mathrm{R}^{2}$ valuewas found to be $96.91 \%, 99.64 \%$ and $99.78 \%$ for RRSS, RRS and RRC respectively.

- The variables having p-values less than 0.05 which indicates that the developed model is a reliable model.

- Composite desirability of optimization was found 0.8425 which indicate the good mathematical correlation between input and responses.

- Optimum values of process parameters are Temperature, Soil Layer Thickness, Relative Humidity and Soil Grain Size were found $303.3^{\circ} \mathrm{K}, 2.5 \mathrm{~cm}, 40.1 \%, 1.92 \mathrm{~mm}$ respectively.

- Optimum responses were found $10.94 \mathrm{~cm}$ for (Read Range in presence of Clay); 11.02 cm (Read Range in presence of Silt) and $10.97 \mathrm{~cm}$ (Read Range in presence of Sandy Soil).

\section{REFERENCES}

Abdorahimi, D. and Sadeghioon, A.M. 2019.Comparison of Radio Frequency Path Loss Models in Soil for Wireless Underground Sensor Networks. J. Sens. Actuator Netw. 8: 35.

Hsieh, Y. C., Cheng, H. W. and Wu, Y. J. 2011.Key Factors Affecting the Performance of RFID Tag Antennas. Current Trends and Challenges in RFID.

Kim, T. H. and Mapa, L. B. 2017. Investigating the Effect of Temperature in RFID Technology.American Society for Engineering Education. 
Deng, F., Zuo, P., Wen, K., Wu, X. 2020. Novel soil environment monitoring system based on RFID sensor and LoRa. Computers and Electronics in Agriculture 169.

Saarinen, K., Björninen, T., Ukkonen, L. and Frisk, L. 2014. Reliability Analysis of RFID Tags in Changing Humid Environment. IEEE Trans. Compon. Packag. Manuf. Technol. 4: 77-85, 2014.

Manzari, S., Occhiuzzi, C., Nawale, S., Catini, A., Natale, C. D.andMarrocco, G. 2012.Humidity Sensing by Polymer-Loaded UHF RFID Antennas. IEEE Sens. J.12: 28512858.

Choudhary, S., Purohit, H., Sehgal, A. and Kaushik, A. 2019.Performance Study of Detectability of RFID System With Varying Atmospheric Conditions. 2019 IEEE 10th Annual Ubiquitous Computing, Electronics \& Mobile Communication Conference (UEMCON), New York City, NY, USA.

Pichorim, S., Gomes, N., Batchelor, J. 2018. Two solutions of soil moisture sensing with RFID for landslide monitoring.Sensors 18.

Choudhary, S., Sharma, A., Gupta, S., Purohit, H., Sachan, S. 2020.Use of RSM Technology for the Optimization of Received Signal Strength for LTE Signals under the Influence of Varying Atmospheric Conditions.EVERGREEN Joint Journal of Novel Carbon Resource Sciences \& Green Asia Strategy. 07: 500-509.

Awad, O.I., Mamat, R., Ali, O.M., Azmi, W.H., Kadirgama, K., Yusri, I.M., Leman, A.M. and Yusaf, T. 2017.Response surface methodology (RSM) based multi-objective optimization of fuel oil-gasoline blends at different water content in SI engine. Energy Conversion and Management 150: 222-241.

Sarıkaya, M. and Güllü, A. 2014.Taguchi design and response surface methodology-based analysis of machining parameters in CNC turning under MQL. Journal of Cleaner Production 65: 604-616.

Sharma, A., Singh, Y., Tyagi, A., Singh, N. 2020.Sustainability of the Polanga Biodiesel Blends during the Application to the Diesel Engine Performance and Emission ParametersTaguchi and RSM Approach. Journal of the Brazilian Society of Mechanical Sciences and Engineering 42. 